\title{
Aplicativos em sala de aula para o ensino de português: aproveitamento de diferentes possibilidades para um mesmo tema
}

\section{Classroom apps for teaching Portuguese: taking advantage of different possibilities for the same theme}

Lafayette Batista Melo1

Tatiana Melbe da Costa²

\begin{abstract}
Resumo
Este artigo tem como objetivo mostrar os resultados da aplicação de jogos educativos em uma turma do ensino fundamental como metodologia de ensino, na área de Língua Portuguesa, e com o conteúdo de reforma ortográfica. Tal escolha ocorreu para investigar como diferentes aplicativos que tratam de um mesmo tema podem ser usados diferentemente, explorando diversas orientações pedagógicas e sendo avaliados segundo critérios de apresentação, usabilidade e conteúdo relacionado. Através da aplicação de um questionário com os alunos foi constatada a necessidade de inserir os jogos como forma de ensino para melhorar a aprendizagem em sala de aula, mas também observou-se a possibilidade de aproveitar cada um dos aplicativos conforme as condições de uso e o grupo de alunos - ou seja, os critérios de avaliação trazem a possibilidade de verificar qual aplicativo poderia ser mais bem usado, conforme fatores como funcionalidades disponíveis, facilidade de instalação e uso simultâneo por vários alunos.
\end{abstract}

Palavras-chave: Apps. Jogos. Português. Ensino. Aprendizagem.

\begin{abstract}
This article aims to show the results of the application of educational games in an elementary school class as a teaching methodology, in the Portuguese language area, and with the content of orthographic reform. This choice was made to investigate how different applications dealing with the same theme can be used differently, exploring different pedagogical orientations and being evaluated according to criteria of presentation, usability and related content. Through the application of a questionnaire with students, it was found the need to insert games as a way of teaching to improve learning in the classroom, but there was also the possibility of taking advantage of each application according to the conditions of use and the group of students - that is, the evaluation criteria bring the possibility of verifying which application could be best used, according to factors such as available features, ease of installation and simultaneous use by several students.
\end{abstract}

Keywords: Apps. Games. Portuguese. Teaching. Learning.

\section{Introdução}

A Língua Portuguesa como disciplina abrange o estudo da fala, sua escrita e o desenvolvimento de textos dos mais diversos gêneros. $O$ ensino da língua portuguesa é um grande desafio na atualidade, uma vez que o aluno tem pouco contato com a leitura, o que dificulta a escrita. As aulas são geralmente baseadas no livro didático, o que restringe a amplitude dos conteúdos linguísticos e literários a fragmentos de textos e limitam o conhecimento de textos e obras de forma integral.

\footnotetext{
1 Doutor em Psicologia Cognitiva. Instituto Federal da Paraíba, João Pessoa, PB, Brasil. Orcid: https://orcid.org/0000-00032233-8435 E-mail: lafayette.melo@academico.ifpb.edu.br

2 Graduanda em Letras. Instituto Federal da Paraíba, São José do Rio do Peixe, PB, Brasil. E-mail: tatimeljp@gmail.com
} 
Há, contudo, algumas experiências diferenciadas como a de leituras de histórias clássicas no formato de blogs, de minicontos multimodais, de poesia, vídeo e som intermediados por materiais digitais, conforme trata Rojo e Moura (2012), bem como o uso de jogos para contar histórias e de um jogo para reforçar o processo de alfabetização, conforme Ribeiro (2016).

De acordo com essas experiências, para melhorar o ensino e a aprendizagem dos alunos nas aulas de Língua Portuguesa é necessário, além de incentivar o estudo de textos integrais, utilizar uma metodologia de ensino mais interativa e engajadora, que incentive a participação dos alunos nas aulas, a busca por sua aprendizagem e que seja desafiadora. Para isso, o uso das tecnologias pode contribuir, já que estas fazem parte do cotidiano dos jovens e, em algumas escolas, até como ferramenta de ensino.

Utilizar jogos online para o ensino em sala de aula é um grande desafio, mas o jogo como ferramenta de ensino está disponível para utilização pelo professor como aliado no ensino de Língua Portuguesa e, além disso, se mostra como parte de uma metodologia de ensino inovadora que pode trazer resultados satisfatórios para a educação. Como diz Vitória et al. (2013), as crianças que têm dificuldades na aprendizagem podem apresentar resultados satisfatórios com a utilização de jogos educativos, uma vez que durante o uso dos jogos a criança precisa de agilidade e raciocínio rápido, aprende a tomar decisões e, no processo de alfabetização, a criança se familiariza melhor com letras, números e cores.

Este relato tem por objetivo apresentar a aplicação de jogos educativos em uma turma de ensino fundamental e tecer considerações de cunho avaliativo acerca dessa aplicação por meio de análise dos resultados de um questionário aplicado. Além disso, a partir dos estudos de Costa (2019) - que usa critérios de avaliação de aplicativos pedagógicos que tratam simultaneamente a forma de apresentação, a usabilidade e o conteúdo relacionado - este trabalho pretende identificar qual é a melhor forma de usar mais de um aplicativo com o mesmo tema, no caso o da reforma ortográfica.

Este relato visa contribuir para a educação como forma de melhorar o processo de ensino e aprendizagem em sala de aula através do uso de jogos educativos pelo professor, uma vez que estes se apresentam como uma ferramenta que pode ser aliada no processo de ensino.

\section{Fundamentação teórica}

2.1 Jogos educativos no ensino de Língua Portuguesa

Com relação à aplicação das tecnologias na educação de modo mais específico, é possível observar que há ainda uma grande dificuldade em inserir essa prática como metodologia de ensino. Os 
jogos eletrônicos na educação servem como complemento ao trabalho do professor, pois são um novo recurso metodológico que une os conteúdos escolares a situações de diversão e brincadeira, o que facilita a aprendizagem dos alunos (RODRIGUES, 2015, p.30).

De acordo com Fernandes (2010, p.54), apesar do potencial e benefício dos jogos educacionais, pode-se observar que ainda não são tão utilizados na educação, e, para muitos professores, encontrar e utilizar bons jogos continua sendo um desafio. Há ainda uma certa resistência em utilizar os jogos como parte de uma metodologia de ensino, mas é necessário considerar a melhoria que a ludicidade presente na dinâmica dos jogos pode trazer.

Alguns critérios devem ser analisados antes de utilizar um jogo para o ensino em sala de aula, de modo que os objetivos desejados sejam alcançados. A escolha ou adaptação de um jogo com objetivos educativos deve levar em consideração o perfil dos jogadores (temperamentos), os estilos de aprendizagem e os tipos de jogadores (PAULA, 2016, p.38).

Sobre critérios de avaliação de aplicativos (apps) e especialmente jogos para a educação, é importante salientar que Costa (2019) mostrou algo que é aproveitado neste trabalho não apenas para avaliar apps, mas para orientar a sua aplicação em sala de aula. Costa (2019) faz um apanhado de critérios de avaliação que juntam ao mesmo tempo a forma de apresentação, a usabilidade e o conteúdo pedagógico do software, os quais são agrupados com as seguintes descrições: funcionalidade disponível, facilidade de instalação, uso simultâneo por várias pessoas, facilidade de controle operacional, nível de desempenho na ocorrência de falhas, questionamentos do usuário no uso, se o app apresenta resultado final dos usuários resumido, se tem feedback, se os conteúdos são interdisciplinares e se há interatividade. De acordo com o Quadro 1 adiante, o pesquisador testa os apps e dá notas de 0 a 2. O que tiver maior pontuação seria teoricamente o melhor. Nosso trabalho parte desses critérios para analisar na prática da realidade concreta de uma sala de aula, como os alunos aceitarão a experiência e como a avaliação feita antes do uso efetivo pode ajudar a orientar o uso com os alunos.

\begin{tabular}{|l|c|c|c|}
\hline \multicolumn{1}{|c|}{ Critério } & Soletrando & Acentuando & $\begin{array}{c}\text { Ortográfico } \\
\text { Educacional }\end{array}$ \\
\hline Funcionalidades & 2 & 2 & 1 \\
\hline Instalação & 2 & 2 & 2 \\
\hline Simultaneidade & 2 & 0 & 1 \\
\hline Facilidade de controle & 1 & 1 & 1 \\
\hline
\end{tabular}




\begin{tabular}{|l|c|c|c|}
\hline Desempenho & 0 & 2 & 1 \\
\hline Questionamento & 0 & 1 & 0 \\
\hline Resultado final & 1 & 2 & 0 \\
\hline Feedback & 1 & 2 & 0 \\
\hline Interdisciplinaridade & 0 & 1 & 1 \\
\hline Interatividade & 0 & 14 & 8 \\
\hline Total & 9 & 1 & 1 \\
\hline
\end{tabular}

Quadro 1. Avaliação dos Apps.

Fonte: Adaptação de Costa (2019).

A percepção dos professores, em sua maioria, juntamente com o entendimento dos teóricos sobre os jogos eletrônicos, fortalece a compreensão de que a finalidade dos jogos, assim como a de outro recurso tecnológico ou pedagógico, é dar suporte ao professor em sua escolha metodológica, de maneira a complementar seus trabalhos em sala de aula, bem como oferecer aos alunos recursos que facilitem seu desenvolvimento e que estejam dentro dos avanços tecnológicos vivenciados por estes (RODRIGUES, 2014, p.33)

Dessa forma, é possível compreender como o professor os usa como suporte, ou seja, como auxiliam nas aulas dos conteúdos de Língua Portuguesa, de forma a melhorar a aprendizagem com interatividade. $O$ jogo faz parte de um grupo de habilidades que integra a inteligência e está diretamente ligado à aprendizagem, auxiliando na memória, ou seja, facilitando o aprendizado de algo que se queira ensinar (HIGA, 2012, p.16).

De acordo com Fernandes (2010), é de grande importância a escolha dos jogos educacionais que serão trabalhados e o tipo de atividades propostas através dos mesmos, as quais devem apresentar situações apropriadas para serem trabalhadas nesse tipo de mídia, além de considerar não apenas o seu conteúdo, mas também a maneira como o jogo se apresenta e se é próprio para a faixa etária que constituirá o público alvo.

Em muitos aspectos, os jogos eletrônicos possibilitam um melhor ambiente de aprendizado. Os jogos permitem um ajuste de nível de dificuldade conforme as habilidades do jogador, provêm aos jogadores uma interação compartilhada imediata e dão aos jogadores escolhas e controle sobre suas ações (MELO, 2012, p.12). 
Conforme Melo (2012) salienta, com o uso dos jogos educativos, as habilidades do jogador são exteriorizadas. Isso ocorre devido aos desafios que o jogo propõe, à interação compartilhada e à autonomia do aluno na condição de jogador. O professor deve realizar um planejamento prévio para que possa decidir o tipo de jogo que será utilizado com os alunos, de maneira que seja possível encontrar um tipo de software adequado que contemple os conteúdos pretendidos e que ainda seja motivador e possibilite aos alunos aprender ou reforçar seus conhecimentos (RODRIGUES, 2014).

\subsection{0 uso do smartphone como ferramenta pedagógica}

Com tantos recursos facilitadores presentes nas tecnologias de informação e comunicação em geral, e nos jogos em particular, o uso das novas tecnologias inteligentes tende a aumentar e isso se deve às inúmeras vantagens que esse recurso pode oferecer para a educação e o processo de aprendizagem.

A utilização de jogos no ambiente escolar traz muitas vantagens para o processo de ensino e aprendizagem, funcionando como um grande motivador. A criança, através dos jogos, obtém prazer e realiza um esforço espontâneo e voluntário para atingir seus objetivos. Os jogos mobilizam esquemas mentais, estimulam o pensamento, a ordenação de tempo e espaço, integrando variadas personalidades (afetiva, social, motora e cognitiva). Além disso, os jogos favorecem o desenvolvimento de habilidades como coordenação, obediência às regras, senso de responsabilidade, senso de justiça, iniciativa pessoal e grupal (FERNANDES, 2010, p. 10).

De acordo com Pacheco, Pinto e Petroski (2015, p. 3) a tecnologia dos celulares, aliada com a Internet, faz com que as pessoas mudem seus hábitos e atitudes. $O$ celular é uma ferramenta tecnológica usada por praticamente todos os jovens para acessar a Internet, usar redes sociais, jogar online e realizar pesquisas. Com isso, seria importante e necessário aliar essa ferramenta, que faz parte do cotidiano dos jovens, à educação de forma a melhorar o ensino e a aprendizagem.

Todos sabemos que os celulares são verdadeiros computadores portáteis interligados à internet, com inúmeros recursos internos, capazes de filmar, tirar fotos, produzir montagens, gravar o áudio que o usuário desejar, além de oferecerem uma grande variedade de aplicativos (LOPES e PIMENTA, 2017, p. 9)

Segundo Rodrigues (2015, p. 17) antes de abordar usos pedagógicos para o celular, é preciso contrapor algumas opiniões sobre a presença do celular na escola, onde o grande argumento crítico é o que prega ser 0 telefone desnecessário por tumultuar $\mathrm{o}$ andamento das aulas. $\mathrm{O}$ uso do celular em sala 
de aula é proibido em muitas escolas. Apesar do uso e liberação da Internet no ambiente escolar, o professor ainda tem dificuldade de utilizar essa ferramenta em suas aulas.

De acordo com Silva (2012), o uso da tecnologia na educação é um grande desafio, principalmente quando se trata de sua inserção no cotidiano da prática docente. 0 desafio se torna ainda maior quando se trata de utilizar o smartphone como ferramenta de ensino dentro da sala de aula rotineiramente. Levando em consideração as vantagens enumeradas pelo uso de apps, os critérios de avaliação antes do uso efetivo e a peculiaridade do uso de smartphones, especialmente em escolas, procurou-se uma instituição de ensino onde o uso era permitido, acompanhado por um professor e aplicando um questionário com os alunos para posterior comparação com os critérios empregados por Costa (2019).

\subsection{Gamificação}

A gamificação nada mais é do que um modo de produzir engajamento com entretenimento, o que implica na utilização de dinâmicas (padrões regulares como os de certas restrições ou narrativas que levam a emoções), mecânicas (ações de feedback, de desafio ou de cooperação e competições que possibilitam as dinâmicas) e componentes (representações visuais de níveis, pontuação ou avatares que possibilitam concretude ao jogo), conforme Alves (2015) e Orlandi, Duque e Mori (2019).

Há várias formas de inserir a gamificação no dia a dia:

- Gamificação nas atividades empresariais - exemplos envolvem estudo em empresas de desenvolvimento de software com soluções para motivar programadores e analistas de sistemas, conforme Peixoto (2016);

- Gamificação nas várias disciplinas escolares para exercitar conceitos explanados nas aulas, conforme Melo (2019) e

- Gamificação em ambientes virtuais de aprendizagem (implementação de soluções informatizadas e estratégias para o ensino a distância), de acordo com Pedro (2016).

A análise de elementos gamificados nesta pesquisa está mais relacionada com os conteúdos das disciplinas escolares, especialmente a reforma ortográfica da Língua Portuguesa, mas apenas para complementar o estudo, identificando se eventuais elementos gamificados dos aplicativos foram bem explorados e observados de alguma maneira na aplicação realizada na escola. 


\section{Aplicação da metodologia, alguns resultados e análises}

A metodologia consistiu em uma proposta na aplicação de jogos como forma de avaliar a aprendizagem do aluno em sala de aula. A turma escolhida foi $06^{\circ}$ ano B da Escola Estadual Ministro José Américo de Almeida, na cidade de São José do Rio do Peixe - PB. A escolha da turma se deu por ser uma sala formada por alunos repetentes em que os professores têm grande dificuldade de atrair a atenção dos alunos, que se mostram dispersos e desinteressados aos conteúdos expostos em sala de aula.

A turma é formada por 25 alunos, mas apenas 15 frequentam as aulas rotineiramente. A aplicação dos jogos ocorreu em meados de dezembro de 2019. Na ocasião, havia apenas 10 alunos. Todos os alunos presentes afirmaram possuir celular do tipo smartphone, mas apenas 5 estavam com 0 celular, de modo que foram divididos em duplas para realizar a atividade. Como a escola dispõe de WiFi para uso dos alunos, foi possível que eles baixassem os jogos indicados no celular, os quais foram Soletrando, Acentuando e Jogo Ortográfico Educacional, todos os jogos avaliados por Costa (2019) relacionados ao mesmo tema: reforma ortográfica.

A atividade foi realizada durante o período de estágio por um dos coautores deste trabalho que já conhecia a turma e a supervisora da escola, o que facilitou a realização da atividade de aplicação dos jogos. A supervisora da turma foi informada antecipadamente e apoiou a realização da pesquisa, vista como uma forma de melhorar o rendimento e a aprendizagem da turma através de uma atividade engajadora.

No jogo Soletrando, há uma tela de abertura com letras maiúsculas e coloridas e um fundo musical animado. Em seguida, o jogador é direcionado para a página inicial do jogo, onde é possível escolher o intervalo de tempo para cada resposta (que varia entre 40, 50 ou 60 segundos) e quantos jogadores vão participar, com a quantidade máxima de dois. O jogador digita seu nome e dá início ao jogo, sendo possível ainda escolher a voz do narrador. Ao clicar no ícone "ouvir a palavra", esta é emitida com a voz do narrador que foi escolhida anteriormente. Em caso de dúvida, é só clicar novamente no ícone para que a palavra seja repetida. Há ainda a opção "diga", que ajuda o jogador a compreender a palavra a ser digitada. Após digitar a palavra, o jogador clica no ícone "ok" e envia a palavra. Em seguida, aparece a palavra "certo" ou "errado", para indicar se o jogador acertou ou errou, e o jogo procede para a próxima palavra. Os erros e acertos podem ser verificados na opção placar, mas não há feedback das respostas do jogador.

Com o jogo Acentuando, há incialmente uma tela que apresenta várias opções para o jogador escolher: acento agudo, acento circunflexo, acento grave, concursos e meu desempenho, onde é 
possível acompanhar o resultado do jogo com total de erros e acertos. Optando por acento agudo para iniciar, aparecem duas palavras, uma com acento agudo e outra sem acento. 0 jogador deve escolher aquela que apresenta a escrita correta com ou sem acento e, ao clicar na palavra e enviar, aparece a opção "certo", destacada em verde para sinalizar o acerto, ou "errado" em vermelho, para sinalizar o erro, seguida do feedback que apresenta as regras gramaticais para cada situação. É possível voltar à página inicial para escolher outra opção ou acompanhar seu desempenho.

No jogo Ortográfico Educacional, há um início com um fundo musical em uma tela que traz duas opções para o jogador escolher: jogar (destacada em azul) ou treinar (destacada em verde). As duas opções são semelhantes, mas a opção treinar não tem um tempo determinado para resposta, mas somente o tempo total que dura o treino. Ao iniciar o jogo, deve-se clicar no ícone "ouvir" (destacado em amarelo). O jogador deve digitar a palavra corretamente no espaço abaixo desse ícone e clicar em "enviar". Há um tempo marcado de 60 segundos para cada resposta, não há opção com dicas, nem feedback ao final. Quando o jogador envia a palavra, o espaço de digitação já é liberado para a próxima palavra. $\mathrm{O}$ desafio do jogo consiste em obter um maior número de acertos em um menor tempo.

Após os alunos conhecerem os jogos e jogarem em sala de aula e fora do ambiente escolar, na aula seguinte eles responderam a um questionário de satisfação que objetivava analisar a opinião dos alunos com relação à atividade prática com os jogos educativos. Na ocasião, estavam presentes 7 alunos na sala de aula e todos que participaram da atividade responderam ao questionário. Todos os alunos relataram que gostaram da atividade desenvolvida através do uso de jogos educativos pelo celular. Quanto ao uso de smartphone em sala de aula, conforme a Figura 1, 3 alunos relataram que usam frequentemente, 2 alunos que usam apenas às vezes e 2 alunos responderam que não usam smartphone em sala de aula. Com relação aos aplicativos mais utilizados, destacaram o Google para realizar pesquisa, redes sociais como Facebook e Whatsapp e jogos como Free Fire.

\section{Uso do Smartphone em sala de aula}

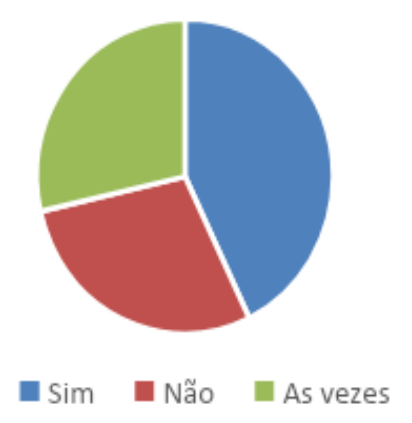

Figura 1. Uso do smartphone em sala de aula

Fonte: Os autores. 
Com relação à utilização de jogos como recurso pedagógico para melhorar a aprendizagem em sala de aula, todos os alunos afirmaram que sim, os jogos contribuem para a melhoria do aprendizado, uma vez que proporcionam uma atividade baseada nos conteúdos trabalhados em sala de aula, mas de forma interativa e dinâmica, o que torna a atividade mais engajadora. Ao serem questionados se 0 uso do celular em sala de aula pode comprometer a aprendizagem, conforme a Figura 2, 3 alunos responderam que sim, afirmando que na maioria das vezes que eles usam o celular estão se conectando às redes sociais ou jogando, 2 alunos responderam que às vezes, pois dependeria do que estariam acessando no celular e 2 alunos responderam e afirmaram que através do celular eles fazem pesquisas e tiram dúvidas sobre os conteúdos estudados.

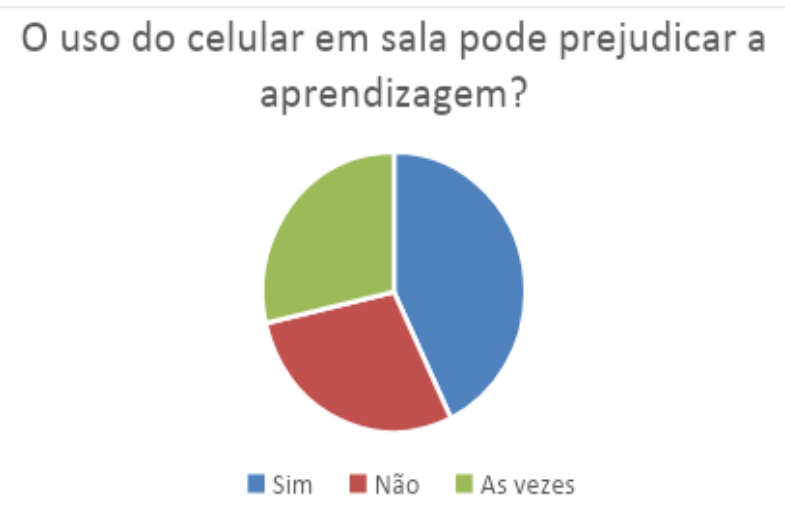

Figura 2. Se o uso do celular prejudica a aprendizagem Fonte: Os autores.

Todos os alunos relataram que usam internet em sala de aula, e dentre os aplicativos mais citados estão as redes sociais Whatsapp, Instagram, Facebook, jogos como Free Fire e o Google para realizar pesquisas.

Grande parte dos alunos, conforme a Figura 3, ainda afirmou que gostaria de usar novas tecnologias como o computador e o celular nas aulas de Língua Portuguesa, de forma a tornar a aula mais divertida o que facilitaria o aprendizado. Nenhum dos estudantes mencionou o uso de Datashow e cerca de 1/4 disse que deveriam ser usadas outras ferramentas tecnológicas, mas, quando abordados sobre quais seriam, trataram de apps ou jogos, o que implica que estariam, na verdade, ainda pensando em computador e Internet. 


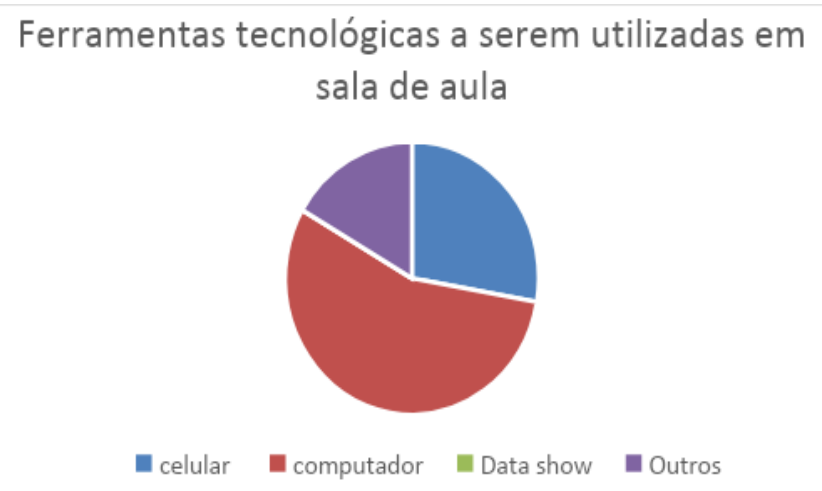

Figura 3 - Ferramentas tecnológicas

Fonte: Os autores.

Considerando que os alunos relataram certa experiência com outros aplicativos, além do Soletrando, do Acentuando e do Ortográfico Educacional, que mesmo ficando incentivados e achando que os apps devem ser mais usados, que (mesmo assim) para uma grande parte poderia haver algum prejuízo (dependendo como fosse feita a aplicação) e que, entre os aplicativos mais citados, a maioria era de redes socias e não de apps educativos, podemos fazer algumas inferências.

A primeira inferência é que a não experiência com jogos de Língua Portuguesa não elimina o desejo dos alunos em aprender e utilizar jogos educacionais, desde que este uso seja delineado pelo professor. A segunda é que os critérios de Costa (2019) podem ser importantes para as escolhas iniciais do pesquisador e do professor, mas que o uso concreto faz com que os alunos e o professor vejam e sempre construam vantagens - não sendo relevante nesta etapa a pontuação total, segundo os critérios de Costa (2019).

Pôde-se notar que explorando diversas orientações pedagógicas (com o app sendo usado para explicitar conceitos ou finalizar a aula com exercícios de um conteúdo já dado) e sendo avaliados segundo critérios de apresentação, usabilidade e conteúdo relacionado para escolha, há um aspecto totalmente diferente no uso concreto. Na aplicação do questionário com os alunos foi constatada a necessidade de inserir os jogos como forma de ensino para melhorar a aprendizagem em sala de aula, mas também observou-se a possibilidade de aproveitar cada um dos aplicativos conforme as condições de uso e o grupo de alunos, ou seja, os critérios de avaliação trazem a possibilidade de verificar qual aplicativo poderia ser mais bem usado, conforme fatores como funcionalidades disponíveis, facilidade de instalação e uso simultâneo por vários alunos, mas, no uso concreto com os alunos, essas características nem são consideradas por aluno e professor. Eles declaram que usam as funcionalidades disponíveis dos apps, mas não mencionam nada sobre a facilidade de instalação; usam individualmente certos recursos de um app, mas o professor pode criar grupos em torno de só um celular; pode ser que o celular 
tenha um ótimo desempenho, mas o sinal de Internet pode o inviabilizar em algum momento; pode ser que os alunos não façam qualquer questionamento no uso mas digam ao final que o resultado foi muito bom ou muito ruim (porque durante o uso preferiam jogar mesmo e não questionar); o app no uso pode não ter feedback, mas o professor pode fornecê-lo; o app pode não ser interativo pelos critérios, mas gerar alta discussão em sala; etc.

Enfim, no uso concreto, os critérios de avaliação se transformam conforme as condições do momento e as atitudes do grupo de alunos que o utiliza. Tal fato nos fez buscar os critérios de gamificação anteriormente mencionados para complementar a análise. Contudo, verificamos que os modos de inserção e, consequentemente, de avaliação da gamificação não são feitos especificamente para análise de apps. Podemos considerar que os programas buscados, testados e aplicados - Soletrando, Acentuando e Jogo Ortográfico Educacional - são certamente apps, mas sob a ótica de serem efetivamente jogos em sua origem não há exatamente esta determinação. Propagandas deles e discussões dos usuários na Play Store podem até se referir aos programas como jogos, mas poderiam ter sido desenvolvidos e publicados na Play Store como softwares educativos, programas para apoio às aulas, testes de conhecimento, etc.

Desse modo, compreendemos que critérios de gamificação mais amplos podem e devem ser usados para ampliar os resultados deste trabalho, já que as discussões dos alunos sobre as razões de uso do smartphone residem em serem divertidos e terem componentes que ressaltam a atividade como gamificada. Apesar de a mecânica dos três programas possuir basicamente o estilo "pergunta-resposta" com dinâmicas em níveis de acerto e erro, há diferentes componentes neles que determinam sucesso ou fracasso como a pontuação, aviso de continuidade ou estrelas e isso deve ser tratado em outros relatos de experiência ou em uma pesquisa.

\section{Considerações finais}

Após o estudo realizado, é possível concluir que o uso de jogos/apps educativos como estratégia de ensino traz resultados satisfatórios, uma vez que se tratam de ferramentas que fazem parte do cotidiano dos jovens e aliá-las à educação pode melhorar o processo de ensino e aprendizagem. № entanto é necessário que os jogos sejam selecionados de acordo com o objetivo pretendido, e conforme o conteúdo a ser aplicado. 0 tema de reforma ortográfica enseja a realização de testes de pergunta e resposta, mas talvez assuntos como sintaxe e certamente 0 de produção textual ensejariam dinâmicas bem diferenciadas. 
O trabalho teve por objetivo apresentar a aplicação de jogos educativos em uma turma de ensino fundamental e, em seguida, tecer considerações de cunho avaliativo acerca dessa aplicação por meio de análise dos resultados de um questionário aplicado a uma turma do $6^{\circ}$ ano. Em sala de aula os alunos baixaram os jogos, jogaram e em seguida responderam a um questionário de satisfação. 0 questionário visou relacionar a opinião dos alunos com o uso de jogos educativos como método de ensino, mas ainda através dessa atividade prática foi possível despertar no aluno uma visão diferente com relação ao uso do celular, que pode ser utilizado de diversas formas para fins educacionais.

Critérios para escolhas dos primeiros testes, antes do uso concreto em sala, são muito importantes, mas essa pesquisa explicitou que provavelmente os critérios devam ser usados exclusivamente para escolha e testes, já que se transformam no uso concreto da sala de aula com aluno e professor e isso pode ser uma contribuição metodológica deste trabalho.

Esse estudo pode contribuir para que os jogos sejam inseridos como metodologia de ensino, seja como aplicativos, seja através de funções específicas. Professores, coordenadores e gestores podem testar a aplicabilidade dos jogos em suas instituições e utilizá-los em sala de aula, tendo em vista a necessidade de inovação na forma de ensino.

De forma mais específica, a opinião dos alunos do ensino fundamental é de que há necessidade de se trazer a tecnologia para as aulas (e.g. jogos de celulares) para compreender um assunto como a reforma ortográfica, o que pode trazer diferentes possibilidades de desenvolver a atividade, conforme 0 estilo dos alunos, os objetivos do professor e a exploração de mecânicas e componentes diferenciados. Nesse caso, os conceitos de gamificação ajudam a esclarecer de forma mais objetiva o que faremos em trabalhos futuros.

\section{Referências}

ALVES, Flora. Gamification: como criar experiências de aprendizagem engajadoras: um guia completo: do conceito à prática. 2. ed. rev. e ampl. -- São Paulo: DVS Editora, 2015.

COSTA, T. Melbe. Jogos e apps para promoção da aprendizagem de língua portuguesa: busca, avaliação e uso, ANAIS do VII SIMELP, Porto de Galinhas, PE, Brazil, 20 a 24 de agosto de 2019.

FERNANDES, Naraline Alvarenga. O uso dos jogos educacionais no processo de ensino e de aprendizagem. Alegrete- RS, 2010.

HIGA, Salete Cristina Arfelli Martini. Jogo pedagógico: facilitador do processo de ensino e de aprendizagem na alfabetização do $1^{\circ}$ ano do Ensino Fundamental I. Medianeira, 2012. 
LOPES, Priscila Almeida; PIMENTA, Cintia Cerqueira Cunha. O uso do celular em sala de aula como ferramenta pedagógica: benefícios e desafios. Revista Cadernos de Estudos e Pesquisas na Educação Básica. Recife, 2017.

MELO, Ivana Raliene Paixão de. O uso de jogos eletrônicos como ferramenta de ensino: um estudo da suíte de jogos Gcompris. Macapá- AP, 2012.

MELO, L. B. Aplicação do Kahoot e do Quizizz para otimizar engajamento nas disciplinas de metodologia de pesquisa. In Proceedings of III Congresso Brasileiro de Informática em Educação - MPIE (2019).

ORLANDI, Tomás Roberto Cotta; DUQUE, Claudio Gottschalg; MORI, Alexandre Mori. Gamificação, uma nova abordagem multimodal para a educação. Biblios, Revista Online. Disponível em:< http://www.scielo.org.pe/pdf/biblios/n70/a02n70.pdf>. Acesso em 12 de Novembro de 2019.

PACHECO, Mariã Aparecida Torres; PINTO, Leandro Rafael; PETROSKI, Fábio Roberto. O uso do celular como ferramenta pedagógica: uma experiência válida. Paraná, 2015.

PAULA, Francisco Leandro de. Gamificação no ensino de Língua Portuguesa: proposta de atividades com gêneros jornalísticos e midiáticos. Mossoró, 2016, 105 p.

PEDRO, L. Z. O uso de gamificação em ambientes virtuais de aprendizagem para reduzir o problema da externalização de comportamentos indesejáveis. Dissertação de mestrado - Mestrado em Ciências da Computação e Matemática Computacional, USP. São Carlos, 2016.

PEIXOTO, M. M. Gamificação para softwares educacionais: um catálogo de requisitos. Dissertação de Mestrado - Mestrado Profissional em Ciência da Computação, Universidade Federal de Pernambuco. Recife, 2016.

RIBEIRO, Ana Elisa. Textos multimodais: leitura e produção. São Paulo: Parábola, 2016.

RODRIGUES, Daniele Mari de Souza Alves. O uso do celular como ferramenta pedagógica. Porto Alegre, 2015.

RODRIGUES, Geovanna Cristina Falcão Soares. Instrumento para avaliação de jogos eletrônicos educativos no ensino fundamental I. João Pessoa- PB, 2015.

ROJO, Roxane; MOURA, Eduardo. Multiletramentos na escola. São Paulo: Parábola editorial, 2012.

SILVA, Marley Guedes da. O uso do aparelho celular em sala de aula. Macapá- AP, 2012.

VITORIA, Cleber; ALEXANDRINI, Fabio; FAVERI, José Ernesto De; ALEXANDRINI, Carla F. D.; MUNZLINGER, André. Uso dos Jogos Educativos como Ensino Aprendizagem na Escola. Anais do $X$ Simpósio de excelência em Gestão e Tecnologia, 2013.

Data de submissão: 21/09/2020. Data de aprovação: 27/10/2020. 